Рыкова Инна Николаевна, Шкодинский Сергей Всеволодович, Юрьева Анна Александровна

\title{
ЛУЧШИЕ ЗАРУБЕЖНЫЕ ПРАКТИКИ ПО ВНЕДРЕНИЮ И РЕАЛИЗАЦИИ МЕХАНИЗМА ЛЬГОТНОГО КРЕДИТОВАНИЯ АГРОПРОМЫШЛЕННОГО КОМПЛЕКСА
}

Особенности современного сочиально-экономического развития России и ее геополитического положения предопределили выбор сельскохозяйственной сферы в качестве приоритета современной государственной политики. В последние годы проблемы развития агропромыциенного комплекса (далее - АПК) активно обсуждаются как на законодательном, так и на исполнительном уровнях, регулярно проводятся круглые столы, форумы, специализированные семинары, на которых рассматриваются программы развития АПК, механизмы поддержски сельского хозяйства и укрепления его материально-технической базы. В этой связи особую актуальность приобретают вопросы совериенствования инструментов поддержск сельхозпроизводителей, в том числе с учетом лучиих зарубежсыхх практик.

Ключевые слова: агропромышленный комплекс, государственная поддержка, льготы, кредитование, зарубежснье практики, Европейский Союз, сельское хозяйство, субсидирование.

\section{Inna Rykova, Sergey Shkodinsky, Anna Yurieva BEST FOREIGN PRACTICES IN THE IMPLEMENTATION AND EXECUTION OF THE MECHANISM OF BENEFICIAL CREDITING OF AGRO-INDUSTRIAL COMPLEX}

The peculiarities of modern socio-economic development of Russia and its geopolitical position predetermined the choice of the agricultural sphere as a priority of modern state policy. In recent years, the problems of the development of the agro-industrial complex (hereinafter referred to as the AIC) have been actively discussed both at the legislative and the executive levels, and round tables, forums and specialized seminars are regularly held to discuss programs for the development of the agro-industrial complex, mechanisms for supporting agriculture and strengthening its material-technical base. In this regard, issues of improving tools to support agricultural producers, including taking into account the best foreign practices, are of particular relevance.

Key words: agriculture, government support, benefits, lending, foreign practices, the European Union, agriculture, subsidizing

Bведениe / introduction. Как известно, Постановлением Правительства РФ от 29.12.2016 № $1528 \mathrm{C}$ с 1 января 2017 г. введен в действие новый механизм государственной поддержки предприятий АПК - льготное краткосрочное и инвестиционное кредитование по ставке не более 5 \% годовых [5]. Эксперты считают, что это значительный шаг вперед в вопросах снижения финансовой нагрузки на сельхозпроизводителей, т. к. существенно упрощается процедура получения кредита, увеличивается срок долгосрочного кредитования до 15 лет, расширяется количество уполномоченных банков и т. д. Однако рисков в сельскохозяйственной сфере остается достаточно много [1, с. 15]. В частности, лимит субсидий не позволяет удовлетворить все кредитные заявки. Некоторые специалисты отмечают также появление элементов коррупционной составляющей, сложности с переводом банками потенциальных заемщиков в реестр заемщиков и др. Именно поэтому Минсельхоз России в феврале 2018 г. провел совещание по вопросам внесения изменений 
в нормативные правовые акты, регламентирующие механизм льготного кредитования [3]. В этой связи особую актуальность приобретает оценка зарубежного опыта по внедрению и реализации механизма льготного кредитования сельхозпроизводителей, чему и посвящена настоящая статья.

Maтериалы и методы / Materials and methods. Подчеркнем, что ограниченный формат статьи не позволяет проанализировать весь спектр лучших зарубежных практик поддержки сельскохозяйственных предприятий, поэтому объекты нашего исследования ограничены отдельными развитыми и развивающимися странами мира (Австралия, Бразилия, Канада). При этом авторы оставляют за собой право продолжить анализ на примере стран американского и азиатского континентов, который позволит получить полноценную картину применяемых зарубежными странами механизмов поддержки фермерских хозяйств в интересах их адаптации и имплементации в российскую практику. В ходе исследования авторы использовали статистический, аналитический методы, а также методы сравнения и аналогии.

Pезультаты и обсуждение / Results and discussion. Австралия. Правительство Австралии помогает фермерам управлять рисками своего бизнеса, предупреждать, а также справляться с ними, в частности, преодолевать последствия засухи и других чрезвычайных ситуаций. В дополнение правительственной помощи в Австралии также оказывается поддержка фермеров со стороны соответствующего штата или территории.

Можно выделить следующие меры правительственной поддержки, оказываемой фермерам в Австралии:

1. Поддержка в виде пособия фермерским домохозяйствам. Пособие фермерского домохозяйства (FHA) [7] предоставляется до четырех лет в рамках совокупной поддержки фермеров, испытывающих финансовые трудности. Цели программы: улучшение финансового положения фермерского домохозяйства с выделением суммы до 4000 австралийских долларов [10].

В 2018-2019 гг. предусмотрена дополнительная доплата к FHA на общую сумму до 12000 австр. долларов для хозяйств, соответствующим определенным критериям [10].

2. Программа по борьбе с сорняками и вредителями [7]. Правительство Австралии выделяет 25,8 млн австр. долл. ежегодно в течение четырех лет для борьбы с негативным воздействием животных и сорняков в районах, пострадавших от засухи. Финансирование предназначено для проектов, направленных на борьбу с вредителями, сорняками, а также улучшение плодородия почвы, качества воды.

3. Программа управления фермерскими рисками [7]. Программа управления сельскохозяйственными рисками призывает фермерские хозяйства использовать варианты страхования для защиты от засухи и других производственных рисков. Программа предоставляет единовременные скидки на консультационную помощь фермерам по подготовке документов для оформления страхового полиса. Скидка составляет половину расходов, понесенных фермерами, но не более 2500 австр. долларов [10].

4. Меры налогообложения.

4.1. Ускоренная амортизация для стимулирования инвестиций в целях эффективного противодействия засухе [7]. Так, затраты на водохозяйственные объекты, активы кормовой инфраструктуры и ограждения могут быть вычтены в течение 1 года.

4.2. Схема управления депозитами фермы (FMD) [7]. FMD позволяет производителям аккумулировать доходы до налогообложения от основного производства в годы с высоким доходом, чтобы использовать его в последующие менее благоприятные годы.

4.3. Усреднение подоходного налога [7]. Усреднение подоходного налога позволяет фермерам выровнять свои платежи по налогу в годы с высоким и низким доходом, подлежащим уплате в течение максимум пяти лет, гарантируя, что фермеры не уплачивают больше налога в течение обозначенного срока 
При этом фермеры смогут воспользоваться данной мерой поддержки только через 10 лет после того, как они отказались от использования данной схемы налогообложения. Например, фермеры, которые отказались от усреднения подоходного налога в 2006-2007 годах, могут воспользоваться данной схемой в 2017-2018 финансовом году, если их налогооблагаемый доход от первичной продукции в данный период больше, чем в предыдущем году.

5. Региональная инвестиционная корпорация (RIC). Региональная инвестиционная корпорация предоставляет кредиты фермерским хозяйствам и реализует кредитный механизм Национальной водной инфраструктуры. RIC была учреждена в Австралии 1 июля 2018 года в соответствии с Законом о региональных инвестиционных корпорациях 2018 года (RIC Act) [10].

Отметим, что доступны два вида кредитов для фермеров - ссуды на инвестиции в сельское хозяйство и ссуды на случай засухи. Инвестиционные кредиты фермерам направлены на диверсификацию фермерской продукции, предназначенной для внутреннего рынка и на экспорт. Займы в случае засухи, предназначены для преодоления последствий засухи, а таюже предотвращения возможных последствий ее наступления.

RIC предлагает 10-летний кредит на сумму до 2 млн австр. долларов, при этом фермеры могут подать заявку в любое время года. Кредиты могут быть использованы также для рефинансирования существующего кредита или получения возможности взять новый кредит путем покрытия операционных расходов и части капитала.

Кредиты на создание, развитие и модернизацию инфраструктуры водоснабжения предоставляются соответствующим государственным и территориальным органам для финансирования государственных и государственно-частных проектов, направленных на строительство и реконструкцию плотин, водосливов, трубопроводов и сооружений для очистки сточных вод. RIC предоставляет указанные кредиты сроком на 15 лет и на сумму 50 и более млн австр. долларов.

Бразилия. В Бразилии сельскохозяйственный кредит является основным источником государственной поддержки как коммерческих, так и семейных фермеров. Национальная система сельских кредитов (Sistema Nacional do Credit Rural, SNCR) предоставляет кредиты фермерам по льготным процентным ставкам. Кредиты предназначены для улучшения маркетинга, наращивания оборотного капитала и роста инвестиций. Можно выделить следующие кредитные программы: Programa ABC, Moderagro, Moderinfra, Moderfrota, PSI Rural, Prodecoop, Pronamp, Procap-Agro, Inovagro и PCA. Кредит для семейных фермерских хозяйств на оборотный капитал и инвестиционные займы предоставляется в рамках программы ПРОНА-Кредит МДА [8].

Льготные процентные ставки по этим кредитам финансируются Бразильским банком развития (BNDES) и «обязательными ресурсами» (Exigibilidade dos Recursos Obrigatórios). Последнее означает, что бразильские банки обязаны использовать не менее 34 \% своих депозитов для предоставления кредитов в сельскохозяйственную сферу по процентной ставке ниже рыночной. Чтобы обеспечить эти льготные кредиты, правительство компенсирует банкам часть затрат на снижение процентной ставки.

Конкретные сельскохозяйственные секторы получают значительную выгоду от этих кредитных программ и целенаправленной налогово-бюджетной политики. Например, правительство Бразилии поощряет производство биотоплива, масличных культур и др. Строительство хранилищ этанола финансируются государством в рамках программы Moderinfra, также создана специальная кредитная линия для производителей сахара (Prorenova).

Кроме того, поскольку большой объем непогашенной задолженности является давней проблемой в сельском хозяйстве Бразилии, кредитная поддержка предоставляется путем реструктуризации задолженности. Как для крупных, так и для мелких фермеров в течение 1990-х и 2000-х гг. было проведено несколько реструктуризаций долговых обязательств, которые включали снижение процентных ставок по просроченной задолженности и продление сроков ее погашения. 
Следует отметить, что государственная поддержка бразильских сельхозпроизводителей предоставляется в основном за счет суббсидируемых кредитов и дополняется мерами поддержки цен и сельскохозяйственным страхованием, которые направлены на стабилизацию цен на сельскохозяйственную продукцию и защиту доходов как крупных, так и семейных фермеров.

Например, бразильское правительство стремится смягчить «колебания〉 в доходах фермеров, поддерживая комбинированное и «доходное» страхование. Эта форма поддержки реализуется через 4 основные программы (Programa de Garantia da Atividade Agropecuária (PROAGRO), Programa de Subvenção ao Prêmio do Seguro Rural (PSR), PROAGRO-MAIS / SEAF, Programa Garantía-Safra (GS) в соответствии с которыми либо выплачивается часть страховой премии фермерам, либо компенсируются их производственные потери, вызванные стихийными бедствиями [8].

Минимальные гарантированные цены также остаются важной мерой сельскохозяйственной политики Бразилии и направлены на защиту фермеров от резкого падения рыночных цен. Национальное агентство по снабжению продуктами питания (Companhia Nacional de Abastecimento, CONAB) является регулирующим органом, отвечающим за реализацию этой политики.

Конкретные меры ценовой поддержки для крупного фермерства включают прямые государственные закупки (Aquisição de Governo Federal, AGF) и финансовую поддержку хранилищ со стороны FEPM (Financiamento para Estocagem de Produtos Agropecuários), реализующей политику обеспечения гарантийных услуг.

Меры поддержки, ориентированные на мелких фермеров, также включают государственные закупки (Programa de Aquisição de Alimentos, PAA) и программы минимальных цен (Programa de Garantia de Preços para a Agricultura Familiar, PGPAF).

Инструменты минимальных гарантированных цен охватывают более тридцати культур, включая хлопок, кукурузу, рис, сою и пшеницу, а также региональные культуры, такие как асаи, маниока, бобы, гуарана, сизаль и некоторые продукты животноводства, такие как молоко и мед. Например, цена поддержки на тонну составляла 231 доллар за пшеницу, 128 долларов за кукурузу и 224 доллара за рис в 2015 году [8]. Порядка 2,6 млрд реалов выделяется на маркетинговую поддержку (закупки федерального правительства, опционные контракты, премия за повышение качества продукции и пр.) и 600 млн реалов составляет субсидирование сельскохозяйственного страхования. Для поддержки сектора по производству кофе (Фонд поддержки по производству кофе) выделено финансирование на сумму 4,9 млрд реалов.

Процентные ставки по субсидируемым кредитам снижены в исследуемом периоде до $6 \%$ в год для средних производителей (с годовым валовым доходом до 2 млн реалов) и до $7 \%$ в год для остальных сельскохозяйственных товаропроизводителей. Процентные ставки по инвестиционному кредитованию установлены в диапазоне от 5,25\% до 7,5\% годовых. Часть средств, аккумулированных в Фонде гарантирования кредитов (Letras de Crédito do Agronegócio), будет использована для дополнительного кредитования сельхозпроизводителей с процентной ставкой до $8,5 \%$ в год.

Другими важным моментом является увеличение объемов государственной поддержки в части финансирования строительства складов вместимостью до 6 тыс. тонн мелкими и средними сельскохозяйственными товаропроизводителями, а также на восстановление земельных фондов и заповедников в рамках программы АВС. Для этих целей правительство предоставляет льготные кредиты с процентными ставками 5,25\% годовых.

Финансирование программы АВС, которая также направлена на стимулирование устойчивых методов и технологий ведения сельского хозяйства, было увеличено с 2,2 млн реалов до 5 млн реалов.

Льготное краткосрочное кредитование отрасли животноводства включает: предоставление кредитов сроком до 2 лет на содержание молочного стада, свиней, коз и овец, а также предусмотрено финансирование до 50 млн реалов на цели пополнения оборотного капитала для молочных сельскохозяйственных кооперативов со ставкой 7 \% годовых и сроком выплаты 12 месяцев. 
Владельцы крупного рогатого скота могут также рассчитывать на получение кредитов в целях приобретения, разведения или выращивания КРС, с фиксированными процентными ставками в размере $7 \%$ в год и лимитом в 450000 реалов на одного заемщика в соответствующем сельскохозяйственном году.

В целях повышения продуктивности скота и качества стада было увеличено финансирование программы Inovagro (Программа стимулирования технологических инноваций в сельскохозяйственном производстве), объемы финансирования увеличены с 330 тыс. реалов до 650 тыс. реалов на получателя.

Кроме того, было увеличено финансирование по программе Pronamp (Национальная программа поддержки доходов сельскохозяйственных товаропроизводителей). Теперь объем финансирования составляет 2 млн реалов (было 1,76 млн реалов) и отменено условие, что доход от сельскохозяйственной деятельности должен составлять не меньше $80 \%$ от общего дохода сельскохозяйственного товаропроизводителя.

Отметим, что в Бразилии начала действовать правительственная «Программа по сельскому хозяйству и животноводству 2018-1919 гг.», на которую в бюджете зарезервировано до 194,3 млрд реалов $(51,13$ млрд долларов США). Эти средства будут распределяться в виде займов для содействия крупным и средним сельскохозяйственным производителям, в частности, на возмещение расходов, инвестиции, коммерциализацию и субссидирование сельского страхования.

Канада. Особенно интересным представляется опыт кредитной поддержки сельскохозяйственных товаропроизводителей в Канаде. Канада - страна с высокоэффективным сельским хозяйством, один из крупнейших в мире экспортеров продовольствия. Государство не только полностью обеспечивает свои внутренние потребности в основных видах продукции, но и является крупным экспортером пшеницы и растительного масла.

Для проведения весенне-полевых работ в Канаде предоставляются беспроцентные авансовые кредиты, а осенью - беспроцентные кредиты, что позволяет сельскохозяйственным товаропроизводителям отсрочить сбыт сезонной продукции.

Основой сельскохозяйственного кредитования выступает Фермерская кредитная корпорация, созданная в 1959 году. Она выдает кредиты на приобретение земельных участков, строительство и реконструкцию зданий и сооружений, приобретение скота, машин, оборудования, удобрений, семян. Срок кредитования составляет от 10 до 30 лет [2, с. 341]. Экономическое положение заемщика является основой определения лимита выдаваемых сумм.

Корпорацией предоставляются кредиты под залог земли, оборудования, скота. Для молодых сельскохозяйственных товаропроизводителей (до 45 лет) [2, с. 342] действует облегченный порядок выдачи кредита. Также корпорацией предоставляются кредиты на покупку машин и оборудования объединениям фермеров (три и более фермеров).

В Канаде действует более двадцати программ поддержки сельского хозяйства, которые различаются по целям, направлениям и механизмам реализации. Среди них:

1) Программа агрострахования: Компонент Национальной промышленной ассоциации (AgriAssurance Program: National Industry Association Component). Оказывает поддержку на национальном уровне, чтобы помочь промышленности разработать и принять системы, стандарты и инструменты для поддержки качественных характеристик, требований по охране здоровья и безопасности канадских сельскохозяйственных и агропродовольственных продуктов;

2) Программа Агриконкурентоспособности (AgriCompetitiveness Program) предоставляет соответствующие суб́сидии, чтобы помочь сельскохозяйственному сектору использовать, координировать и наращивать существующий потенциал, обмениваться передовым опытом, предоставлять возможности наставничества, а также оказывать информационную поддержку фермерам, реализовывать инструменты обеспечения безопасности фермерских хозяйств. 
3) Канадская программа Закона о сельскохозяйственных кредитах (CALA) предназначена для повышения доступности кредитов для фермеров и сельскохозяйственных кооперативов. Фермеры могут использовать эти кредиты для создания, улучшения и развития фермерских хозяйств, в то время как сельскохозяйственные кооперативы получают кредиты на цели переработки, распределения и сбыта продукции сельского хозяйства.

Посредством программы CALA правительство Канады поддерживает модернизацию сельскохозяйственного сектора и позволяет кооперативам лучше использовать рыночные возможности. Федеральное правительство гарантирует кредитору погашение $95 \%$ чистого убытка по выданному кредиту [4]. Максимальный совокупный кредитный лимит для одной фермы составляет 500000 долларов. При этом в зависимости от целей:

- 500000 долл. на покупку земли и строительство или благоустройство зданий;

- 350000 долл. на другие цели кредитования, включая консолидацию / рефинансирование [4].

При этом максимальный совокупный кредитный лимит для сельскохозяйственных кооперативов составляет 3 млн долларов.

Следует отметить, что в целом государственная поддержка в Канаде реализуется путем реализации следующих механизмов: выделение льготных кредитов для компенсации производственных затрат; использование налоговых льгот для поддержания доходности сельскохозяйственного производства; применение ценовых надбавок к рыночным ценам для обеспечения доходности сельхозпродукции; выдача гарантий по кредитам; оказание поддержки в области сельскохозяйственного страхования.

Заключение / Conclusion. Как показал анализ лучших зарубежных практик, механизм льготного кредитования имеет достаточно разнообразный инструментарий. Оценка опыта таких стран, как Австралия, Бразилия и Канада демонстрирует специфику его применения, а отличительные черты, как правило, связаны с историческими, экономическими, правовыми и иными особенностями исследуемых государств.

Можно сделать предварительный вывод о том, что в большинстве зарубежных стран предоставление кредита (кредитной линии) сельскохозяйственным товаропроизводителям является приоритетной мерой государственной поддержки, в ходе реализации которой государство активно участвует как в создании благоприятных условий, так и в формировании нормативно-правовой базы функционирования системы сельскохозяйственного кредитования.

Как представляется, полноценные выводы могут быть получены при расширении спектра обследуемых стран, а также при сопоставлении сравнительных показателей механизма государственной поддержки и механизма льготного кредитования АПК в зарубежных странах с накопленным передовым опытом.

\section{ЛИТЕРАТУРА И ИНТЕРНЕТ-РЕСУРСЫ}

1. Боговиз А. В. Оценка действующих мер государственной поддержки сельского хозяйства в условиях импортозамещения / А. В. Боговиз, Ю. В. Рагулина, С. В. Шкодинский, И. А. Продченко // Экономика сельскохозяйственных и перерабатывающих предприятий. 2017. № 4. С. 13-18.

2. Кибиров А. Я., Бурых Е. Е. Зарубежный опыт организации сельскохозяйственного кредитования // Аграрный вестник Урала. 2011. № 4 (83). С. 89-91.

3. Минсельхоз России: механизм льготного кредитования аграриев продолжает совершенствоваться // Официальный сайт Министерства сельского хозяйства Российской Федерации [Электронный ресурc]. URL: http: http://mcx.ru/press-service/news/mekhanizm-lgotnogo-kreditovaniya-agrarievprodolzhaet-sovershenstvovatsya/ дата обращения 04.02.2019)

4. Министерство сельского хозяйства и продовольствия Канады [Электронный ресypc]. URL: http:// www.agr.gc.ca/eng/programs-and-services/?id=1362151577626 (дата обращения 04.02.2019)

5. О кредитовании сельскохозяйственных товаропроизводителей по льготной ставке // Официальный сайт Правительства Российской Федерации. [Электронный ресурc]. URL: http://government.ru/ docs/25950/ дата обращения 23.01.2019)

6. Шкарупа Е. А. Зарубежный опыт сельскохозяйственного кредитования: возможности использования в российских условиях // Экономика: вчера, сегодня, завтра. 2017. Том. 7. № 5В. С. 340-350. 
7. Department of Agriculture, Environment and Rural Affairs (DAERA) Balance sheet analysis and farming performance, England 2017/2018, январь 2019 года. [Электронный ресурc]. URL: https://www.daera-ni. gov.uk (дата обращения: 24.01.2019)

8. Farm Europe: Yves Madre \& Pieter Devuyst How to deal with price and income fluctuations for farmers? Review of international agricultural policies and instruments (Как бороться с колебаниями цен и доходов для фермеров? Обзор международной сельскохозяйственной политики и инструментов), 2016 год. [Электронный ресурc]. URL: https://www.farm-europe.eu/travaux/how-to-tackle-price-and-incomevolatility-for-farmers-an-overview-of-international-agricultural-policies-and-instruments (дата обращения 23.01.2019)

9. Ministério da Agricultura, Pecuáriae Abastecimento. [Электронный ресурc]. URL: http://www.agricultura. gov.br/assuntos/sustentabilidade/plano-agricola-e-pecuario (дата обращения 24.01.2019)

10. Regional Investment Corporation. [Электронный pecypc]. URL: http://www.ric.gov.au (дата обращения 23.01.2019)

\section{REFERENCES AND INTERNET RESOURCES}

1. Bogoviz A. V. Otsenka deist-vuyushchikh mer gosudarstvennoi podderzhki sel'skogo khozyaistva v usloviyakh importozameshcheniya (Evaluation of existing measures of state support of agriculture in the conditions of import substitution) / A. V. Bogoviz, Yu. V. Ragulina, S. V. Shkodinskii, I. A. Prodchenko // Ekonomika sel'skokhozyaistvennykh i pererabatyvayushchikh predpriyatii. 2017. № 4. S. 13-18.

2. Kibirov A. Ya., Burykh E. E. Zarubezhnyi opyt organizatsii sel'skokhozyaistvennogo kreditovaniya (Foreign experience in the organization of agricultural lending) // Agrarnyi vestnik Urala. 2011. № 4 (83). S. 89-91.

3. Minsel'khoz Rossii: mekhanizm l'gotnogo kreditovaniya agrariev prodolzhaet so-vershenstvovat'sya // Ofitsial'nyi sait Ministerstva sel'skogo khozyaistva Rossiiskoi Fede-ratsii. [Elektronnyi resurs]. URL: http://mcx.ru/press-service/news/mekhanizm-lgotnogo-kreditovaniya-agrariev-prodolzhaet-sovershenstvovatsya/ data obrashcheniya 04.02.2019)

4. Ministerstvo sel'skogo khozyaistva i prodovol'stviya Kanady. [Elektronnyi resurs]. URL: http://www.agr. gc.ca/eng/programs-and-services/ $/ \mathrm{id}=1362151577626$ (data obrashcheniya 04.02 .2019 )

5. O kreditovanii sel'skokhozyaistvennykh tovaroproizvoditelei po l'gotnoi stavke // Ofitsial'nyi sait Pravitel'stva Rossiiskoi Federatsii. [Elektronnyi resurs]. URL:http://government.ru/docs/25950/ data obrashcheniya 23.01.2019)

6. Shkarupa E. A. Zarubezhnyi opyt sel'skokhozyaistvennogo kreditovaniya: vozmozhno-sti ispol'zovaniya $\mathrm{v}$ rossiiskikh usloviyakh (Foreign experience in agricultural lending: the possibility of using in Russian conditions) // Ekonomika: vchera, segodnya, zavtra. 2017. Tom. 7. № 5V. S. 340-350.

7. Department of Agriculture, Environment and Rural Affairs (DAERA) Balance sheet analysis and farming performance, England 2017/2018, yanvar' 2019 goda. [Elektronnyi resurs]. URL: https://www.daera-ni. gov.uk (data obrashcheniya: 24.01.2019)

8. Farm Europe: Yves Madre \& Pieter Devuyst How to deal with price and income fluctuations for farmers? Review of international agricultural policies and instruments (Kak borot'sya s kolebaniyami tsen i dokhodov dlya fermerov? Obzor mezhdunarodnoi sel'skokhozyaistvennoi politiki i instrumentov), 2016 god. [Elektronnyi resurs]. URL: https://www.farm-europe.eu/travaux/how-to-tackle-price-andincome-volatility-for-farmers-an-overview-of-international-agricultural-policies-and-instruments/ (data obrashcheniya 23.01.2019)

9. Ministério da Agricultura, Pecuária e Abastecimento. [Elektronnyi resurs]. URL: http://www.agricultura. gov.br/assuntos/sustentabilidade/plano-agricola-e-pecuario/ (data obrashcheniya 24.01.2019)

10. Regional Investment Corporation. [Elektronnyi resurs]. URL: http://www.ric.gov.au (data obrashcheniya 23.01.2019)

\section{СВЕДЕНИЯ ОБ АВТОРАХ}

Рыкова Инна Николаевна, доктор экономических наук, руководитель Центра отраслевой экономики ФГБУ «Научно-исследовательский финансовый институт Министерства Финансов Российской Федерации». E-mail: rycova@yandex.ru 
Шкодинский Сергей Всеволодович, доктор экономических наук, профессор, главный научный сотрудник Центра отраслевой экономики ФГБУ «Научно-исследовательский финансовый институт Министерства Финансов Российской Федерации». E-mail: sh-serg $a$ bk.ru.

Юрвева Анна Александровна, младший научный сотрудник Центра отраслевой экономики ФГБУ «Научно-исследовательский финансовый институт Министерства Финансов Российской Федерации». E-mail: annsmagina@rambler.ru

\section{INFORMATION ABOUT AUTHORS}

Inna Rykova, Doctor of Economics, Head of the Sectorial Economy Center, The Federal State Budgetary Institution «Financial research Institute of the Ministry of finance of the Russian Federation». E-mail: rycova $a y a n d e x . r u$.

Sergey Shkodinsky, Doctor of Economics, Professor, Chief Researcher of the Sectoral Economy Center, The Federal State Budgetary Institution «Financial research Institute of the Ministry of finance of the Russian Federation». E-mail: sh-serg $a$ bk.ru

Anna Yuryeva, Junior Researcher, of the Sectorial Economy Center, Research Financial Institute, The Federal State Budgetary Institution «Financial research Institute of the Ministry of finance of the Russian Federation». E-mail: annsmagina arambler.ru 